\title{
El rol de internet para romper el silencio: el ejemplo de dos casos en américa latina, Marcelo Freixo en Brasil y Sebastián Piñera en Chile
}

\author{
Camila Pérez Lagos \& Camila Cabral Salles \\ Universidad Sorbonne nouvelle \\ E-mail: perez.lagos.camila@gmail.com/ camilaoumila@gmail.com
}

\begin{abstract}
Resumen
Los medios de comunicación constituyen un espacio privilegiado para que la sociedad hable consigo misma y a propósito de sí misma (França, 2012). Actualmente, la mayoría de los hogares tienen acceso a internet, por consiguiente, a través de este "nuevo media" se logra dar visibilidad a acontecimientos y a hechos que los medias dichos "tradicionales" no quieren tratar o insisten en silenciar. Desde esta perspectiva, y a través de dos ejemplos provenientes de Brasil y de Chile, buscamos profundizar acerca de cómo internet puede ser usado como una herramienta para "romper el silencio" a la luz de las democracias actuales influyendo en la opinión pública (Miège, 2010). Como señala Cardon (2010), internet amplia el espacio público, transformando la naturaleza misma de la democracia. Asimismo, esta reflexión pretende revitalizar la discusión sobre el rol de los medios en línea frente a casos de interés público, quedando a la frontera entre el poder y la ciudadanía. En los casos de Chile y Brasil lo anterior cobra un sentido particular ya que los medios tradicionales, a lo largo de la historia, han estado controlados por los gobiernos y las corporaciones, por lo

que las redes sociales e Internet aparecen como espacios de autonomía (Castells, 2012). En este contexto, se aplicó un análisis sémio-discursivo (Charaudeau, 1995, 2011) a diferentes soportes provenientes de la red que tratan sobre dos casos de figuras políticas, a) la cuenta oficial de Marcelo Freixo en Facebook, y b) los artículos que vinculan a Sebastián Piñera con los "Panamá Papers" de un diario electrónico en chile: El mostrador. El primero corresponde al candidato de la municipalidad de Rio de Janeiro Marcelo Freixo del PSOL, que en 2016, consiguió movilizar una buena parte de la sociedad para llegar al segundo turno de las elecciones, con solo 11 segundos de propaganda electoral autorizada en la televisión y en las radios. El segundo caso corresponde al ex presidente chileno, Sebastián Piñera, quien durante las negociaciones de terreno marítimo en Chile y Perú en la Haya habría realizado inversiones en empresas peruanas que mantenían sede en Panamá gracias a información privilegiada. A continuación se presentan los aspectos teóricos y metodológicos seguido del análisis y los principales resultados de esta investigación.
\end{abstract}

Palabras clave: internet; espacio publico; democracia; Brasil; Chile.

Data de submissão: 31/05/2017. Data de aprovação: 30/06/2017.

A Revista Estudos em Comunicação é financiada por Fundos FEDER através do Programa Operacional Factores de Competitividade - COMPETE e por Fundos Nacionais através da FCT - Fundação para a Ciência e a Tecnologia no âmbito do projeto Comunicação, Filosofia e Humanidades (LabCom.IFP) UID/CCI/00661/2013.
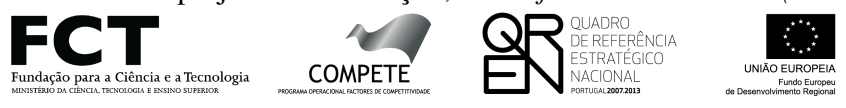

\密离

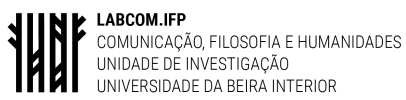




\begin{abstract}
The media are a privileged space for society to talk to itself and about itself (França, 2012). Currently, most households have access to the Internet, therefore, through this "new media"we can give visibility to events and events that the so-called "traditional"media do not want to address or insist on silencing. From this perspective, and through two examples from Brazil and Chile, we seek to deepen on how the Internet can be used as a tool to "break the silence"in light of current democracies influencing public opinion (Miège, 2010). As Cardon (2010) points out, the internet widens the public space, transforming the very nature of democracy. Likewise, this reflection aims to revitalize the discussion on the role of online media in the face of cases of public interest, remaining at the frontier between power and citizenship. In the cases of Chile and Brazil, the above mentioned takes on a particular meaning since traditional media, throughout history, have been controlled by governments and corporations, so that social networks and the Internet appear

as spaces of autonomy ( Castells, 2012). In this context, a semio-discursive analysis was applied (Charaudeau, 1995, 2011) to different media from the network that deals with two cases of political figures, a) the official account of Marcelo Freixo on Facebook and b) the articles from an electronic newspaper in Chile ("El Mostrador") that link Sebastián Piñera with the "Panama Papers. The first corresponds to the candidate of the municipality of Rio de Janeiro Marcelo Freixo of PSOL, who in 2016, managed to mobilize a good part of society to reach the second round of the elections, with only 11 seconds of electoral propaganda authorized on television and on the radios. The second case corresponds to the former Chilean president, Sebastián Piñera, who during the maritime negotiations in Chile and Peru in the Hague had made investments in Peruvian companies that were based in Panama using privileged information. The theoretical and methodological aspects followed by the analysis and the main results of this investigation are presented below.
\end{abstract}

Keywords: internet; public space; democracy; Brazil; Chile.

\title{
1. internet como forma de compromiso político
}

CEGÚn Cardon y Granjon (2013), desde los años 2000 los militantes pueden encontrar en inter$S$ net un espacio particularmente adaptado a la construcción de nuevas formas de movilización y compromiso. Es bien sabido que internet, actualmente, esta ocupando un papel importante durante las campañas políticas electorales en un gran número de democracias. Desde la campaña de Barack Obama en 2008 en los Estados Unidos, muchos trabajos analizaron cómo el uso de las tecnologías modernas puedes ser colocadas a disposición de campañas electorales, transformando la web, las redes sociales y los Smartphone en verdaderas herramientas de divulgación, cuando son utilizadas de manera inteligente e eficaz (Heinderyckx, 2011; Gomes, Fernandes, Reis, Silva, 2009). De hecho, estos soportes pueden desempeñar un papel fundamental y estratégico de inicio a fin de una campaña electoral cuando pensamos, por ejemplo, en la función de reclutamiento de militantes, en la divulgación de propuestas de gobierno en la organización, o en la colecta de donaciones financieras.

Si consideramos los medios como "un espacio privilegiado en el cual la sociedad habla consigo misma y a propósito de si misma" (França, 2012: 12), como explica França (2012), el silencio de algunos hechos en la agenta de los medias tradicionales, puede presentar un peligro, ¿como dar 
visibilidad a los acontecimiento y hechos que los grandes medios no quieren tratar o existen en callar?. Según Cardon (2010) en la era digital, toda democracia cambia de configuración porque la web permite un aumento del espacio público, transformando también la capacidad de participación de los ciudadanos. En sus palabras, este publico "antes sobre control, se emancipa" (Cardon, 2010: 99). Además, sabemos a propósito del universo de internet y su utilización en campañas políticas, que ya han evolucionado bastante hasta el día de hoy ${ }^{1}$. Como señala Gomes (et al., 2009) en un estudio sobre la campaña de Barack Obama, "en una campaña on-line se vio que la visibilidad no se resume a exhibir contenido, como el modelo de web clásico" (Gomes et al., 2009: 39), sino que al mismo tiempo, permite crear herramientas que sensibilicen al público e incentiven la participación y colaboración del mismo.

Contrario a lo que se podría imaginar en los inicios de los estudios sobre comunicación electoral on-line, el papel de las redes sociales va mucho más allá de una agenda electrónica de los candidatos (Russman, 2010; Newell, 2001; Tavares y Massuchin, 2015). Las redes sociales continúan siendo utilizadas para la divulgación de eventos de campaña, pero también poseen una gran importancia cuando las analizamos como fuente de información y compromiso. Por ejemplo, a través de compartir contenido, se pueden alcanzar a ciudadanos que no estaba directamente en contacto con el contenido de la página del candidato en cuestión y que al principio, no demostraban interés por este, ampliando de esta forma la visibilidad de la campaña (además de los electores que estaban dispuesto a conceder su voto). En definitiva, la importancia de las redes en el compromiso de los ciudadanos, tanto en su función on-line como en las consecuencias directas efectuadas por la función off-line, merecen ser percibidas con mayor atención.

De esta misma forma, los medios on-line, pueden ejercer un papel importante como fuente de información alternativa en hechos silenciados por los vehículos de comunicación tradicional. Si penamos en los ejemplos de la campaña de Marcelo Freixo a la prefectura de Rio de Janeiro en 2016 o en la vinculación de Sebastián Piñera en el escándalo de los "Panamá Papers", podemos percibir como dicen Cardon y Granjon (2013) que internet pueden abrir nuevos espacios de visibilidad y distanciarse, en cierta manera de los medias tradicionales.

\section{Internet como espacio de visibilidad}

Por una parte, diversos autores coinciden en el hecho que internet constituye un espacio de visibilidad, es decir, que permite mostrar cuestiones de interés público que los medios tradicionales no necesariamente exponen. En este sentido, la red es comprendida como un "espacio de autonomía en gran medida fuera del control del gobierno y corporaciones que, a lo largo de la historia, han monopolizado los canales de comunicación como cimiento de su poder" (Castells, 2012: 20). Por su parte, Cardon y Granjon (2013) señalan que, actualmente, frente al contexto tecnológico, los movimientos "orientan su acción colectiva hacia la crítica de los medios dominantes y/o a la implementación de dispositivos alternativos de producción colectiva" (Cardon y Granjon, 2013: 8). Es decir, frente a los medios "dominantes", -que están presionados por los lobbies, que buscan el sensacionalismo por sobre la información, y que han sido históricamente los encargados

1. Gomes et al., utilizan los términos "proto web", "web", y "pos-web"para analizar estas transformaciones. 
de reproducir un pensamiento único-, internet y las redes sociales se presenta como un espacio más plural y crítico en el que los ciudadanos tienen "derecho" a tomar la palabra, coordinarse y tratar los temas que les interesen. En este marco, internet constituiría una forma de comunicación horizontal que puede ser manejable por los mismos usuarios (Castells, 2001).

Por otra parte, si bien, muchos creyeron que el desarrollo de la web participativa aseguraría la existencia de un espacio abierto a todos, crítico y transparente, (Cardon y Granjon, 2013), sin embargo hoy internet tampoco esta exento a las críticas que se han hecho a los medios tradicionales. Como plantea Cardon (2010), "cada vez más presentes en internet, los medios, las industrias culturales, los partidos políticos, y las empresas, han encontrado parcialmente, la dominación que ellos ejercen sobre las jerarquías del espacio público tradicional" Cardon, 2010: 101). En este sentido, la cuestión del acceso a los contenidos de internet se torna cuestionable, ya que, como señala Cardon (2010) "con internet, algunas cosas visible no son necesariamente publicas. La web en efecto amplió el espacio público, disociando las nociones de visibilidad y publicidad" (Cardon, 2010: 36). Creemos, que en algunos casos, internet puede ser entendido aun como un medio para la visibilidad que permitiría romper el silencio.

\section{Presentación de la metodología y el corpus}

El estudio fue de carácter exploratorio, el objetivo principal fue determinar las características semiótico-discursivas de dos casos que usaron internet como medio para romper el silencio. Para ello se usó el análisis del discursos "francés" como una herramienta metodológica y de análisis. A través de esta metodología se busca "describir los mecanismos que rigen el aspecto simbólico [de los discursos mediáticos] y las diferentes configuraciones que la hacen visible" (Charaudeau, 2013: 13).

Desde esta perspectiva, se considera que los medios de información funcionan en una doble lógica : económica y semiológica,

"económica según la cual todo órgano informativo actúa como una empresa cuya finalidad consiste en la fabricación de un producto que se define por el lugar que ocupa en el mercado de intercambio de bienes de consumo (y por lo tanto los medios tecnológicos utilizados para fabricarlo forman parte de esta lógica); una lógica semiológica (en sentido amplio) según la cual todo órgano de información debe considerarse como una máquina productora de signos (es decir, de formas y sentidos), que se originan en la parte de la actividad humana dedicada a construir sentido social" (Charaudeau, 2013: 16).

Cabe señalar que como plantea Charaudeau (2011) la información es un asunto principalmente de lenguaje, que es opaco, es decir, que construye una visión o un sentido particular del mundo. Lo anterior se efectúa a través del acto de tematización donde además de generar una fragmentación semántica del mundo (nombrar), los acontecimientos se inscriben en un propósito comunicativo. En otras palabras, a través del discurso, los acontecimientos "se construyen según su potencial de "actualidad", "de "socialidad" y de "imprevisibilidad"" (Charaudeau, 2012: 125). Además, la tematización, se puede focalizar en la causa, en las consecuencias o en los detalles guiadas, ciertamente por un propósito. También, desde esta óptica se puede observar e interpretar del material 
lingüístico-discursivo, como por ejemplo el empleo de los pronombres personales "Nosotros" y "Yo" (Maingueneau, 2011), la designación, la nominación y la memoria de palabras (Moirand, 2007), entre otros.

Como se planteó en la introducción de este artículo, los dos casos merecen ser estudiados con una atención particular, con el fin de analizar el papel de internet, y de las redes sociales con la finalidad de romper el silencio.

En el caso de Brasil, se analizó en particular la campaña de Marcelo Freixo del PSOL, (Partido Socialismo y Libertad). Nuestro corpus esta compuesto de 43 videos publicados por el equipo de Freixo en su pagina de Facebook, en particular, en el espacio dedicado a la campaña del 2016 entre junio y octubre del mismo año. La elección de trabajar solamente con videos, se debe a que se trata de un mensaje audiovisual como en la televisión, es decir, en el medio en el que el candidato había sido "silenciado". El objetivo principal fue identificar e interpretar las estrategias utilizadas por el equipo de comunicación de Freixo para cuestionar ¿cómo internet permite quebrar el silencio de los grandes medios?.

En el caso chileno se identificaron todos los artículos de prensa de un diario electrónico nacional "El mostrador", que vincularan explícitamente a Sebastián Piñera (ex presidente de Chile entre los años 2010 y 2014) y los "Panama Papers". Se seleccionó intencionalmente este medio, que posee una línea editorial de carácter progresista, además de ser el primer diario electrónico de Chile y uno de los sitios de noticias más visitados del país (González y Satt, 2016). Se conformó un corpus con un total de 35 artículos que van desde el día 6 de abril 2016, donde se vincula por primera vez al ex presidente chileno a los "Panama Papers", hasta el 12 de junio 2017 cuando Sebastián Piñera va a un programa de televisión como candidato de las presidenciales de fines del 2017 y explica sus vínculos con las empresas situadas en Panamá.

A continuación se exponen los principales resultados y análisis de los casos, comenzando por el caso brasileño y posteriormente el caso chileno

\section{Cambiar es posible}

Antes de introducir el análisis propiamente dicho, haremos algunas precisiones sobre el contexto político-social de Brasil, además de señalar algunos antecedentes que permitirán situar la figura de Marcelo Freixo. Sobre el primer punto, nos gustaría destacar dos hechos que marcan la historia reciente de Brasil. El primero, corresponde al proceso de "impeachment" sufrido por la entonces presidenta "Dilma Roussef", culminando con su alejamiento, nueve meses, a propósito del inicio del proceso, en mayo de 2016. Con la salida de la presidenta, Michel Temer, su vice-presidente, asume el cargo de presidente, mediante protestas en todo Brasil y polémicas que perduran hasta lo días de hoy. El segundo punto importante para comprender el contexto político vivido por el país fueron las manifestaciones de 2013, también conocidas como "Manifestaciones de Junio", donde millones de personas salieron a las calles para protestas, inicialmente por el aumento de la tarifa del transporte público en las grandes ciudades, que ganaron fuerza, incorporando otros temas a lo largo del mes. En este contexto de crisis social y política, cabe señalar que de la discusión también de hicieron ampliamente en las redes sociales. 
Sobre Marcelo Freixo, cabe señalar que es desde 2007 diputado quien ya había sido candidato a la Prefectura de Rio en 2012, con una campaña que contó con un amplio apoyo de la juventud y de la clase artística, el movimiento se llamó "Primavera Carioca", llegando al segundo lugar con $30 \%$ votos. Como ya señalamos, este análisis trata la campaña realizada por Freixo y su vice prefecta Luciana Boiteux a la prefectura de la ciudad de Rio de Janeiro, en 2016.

Como ya señalamos, en Brasil, el tiempo de la televisión y de radio de cada candidato tiene durante el "Horario Electoral Gratuito" no es equilibrado. Por eso, muchos corren el riesgo de atravesar ese importante proceso democrático sin conseguir ni siquiera un minuto de propaganda electoral autorizada en los medios de comunicación tradicional, mientras que otros partidos y grandes coaliciones consiguen acumular preciosos minutos por día ${ }^{2}$. Marcelo Freixo, quien no quiso buscar alianzas para aumentar su tiempo en Televisión, tuvo 11 segundos durante todo el primer turno. Además de lo anterior, debido a la polémica modificación de la ley 9504/97, Freixo también fue impedido de participar en el debate transmitido en televisión, incluso cuando ocupaba el segundo lugar en las encuestas. Según este texto, solamente los partidos que tenían al menos diez diputados electos podían ser invitados a los debates de televisión. En el caso de los candidatos que no cumplieran esa exigencia, le correspondía a los otro candidatos del debate decidir su presencia ${ }^{3}$. El video publicado el di 8 de agosto, el candidato y su equipo llaman la atención por este hecho. En este video, vemos una intervención efectuada el día 29 de julio, en un tren de la ciudad, con varios jóvenes amordazados. En la primera parte, no hay voces o palabras, apenas mensajes escritos con frases que recuerdan la situación: "se você quisesse apresentar propostas para a cidade e não te deixassem falar. O que você faria?".

Además, el contenido de la reforma política es abordado como un conjunto de reportajes de los grandes medios, finalmente una voz en off anuncia: "é a voz de todos nos que estão querendo calar. Não deixe isso acontecer. Assine a petição". Lo interesante de este reportaje es que Marcelo Freixo, no aparece en ningún momento en el video. Como un intento de hacer que los espectadores se pongan en el lugar de alguien que tiene su voz callada, silenciada, el equipo de Freixo pretende demostrar la gravedad y la falta de espíritu democrático de esta reforma, sin "asustar" a los electores con un vocabulario o campo lexical específico de la política, de difícil comprensión para la mayoría de los electores, (como reformas, códigos, enmiendas, etc.). El hecho de no aparecer en el video, permite también que cualquier ciudadano carioca se identifique con aquel grupo de personas que está utilizando el transporte público, pero que sin embargo, no esta amordazado.

Como una alternativa para quebrar esta "invisibilidad" en los medios tradicionales de comunicación, además de la ausencia de debate, Marcelo Freixo, convocó a la población a participar del debate en una plaza pública. En el mismo momento que sus competidores estaban en la emisora. Freixo va a Cinelândia, tradicional lugar de espacios políticos en el centro de Rio, para responder y comentar las preguntas que estaban siendo hechas a los participantes en el estudio. El evento

2. Según la legislación brasileña, el tiempo atribuido a cada candidato es proporcional al numero de representantes en la cámara de diputados. El "Horario Gratuito" de propaganda electoral es transmitido durante el día y la noche, y en general tiene un papel fundamental para la visibilidad de los candidatos.

3. Debido al carácter anti-democrático de esta propuesta, el STF aceptó la queja de Freixo y de los otros candidatos que se encontraban en la misma situación y autorizó a las redes de televisión a invitar a todos los candidatos que la emisora decidiera. 
organizado por Freixo tenia, evidentemente, una transmisión en vivo en las redes sociales. Si prestamos atención a otras campañas políticas, verificamos que esta práctica ya había sido propuesta por el PSOL, partido de Freixo, con algunas diferencias importantes. En la campaña presidencia del año 2010, el entonces candidato Plinio Arruda no había sido convidado al debate virtual del UOL7 y promovió un "debate virtual paralelo" (transmitido on-line), donde se proponía comentar y responder a las cuestiones del debate "original". Con esta iniciativa, Plinio Arruda, se transformó en tending topics del Twitter brasileño, generando así mas comentarios que sus tres otros contrincantes que habían sido invitados al debate (Jamil y Sampaio, 2011). Podemos decir que la estrategia de Freixo usada en 2016 para ser visible frente al debate al cual no había sido invitado, ya había sido adoptada por un compañero de partido, sin embargo, podemos verificar una especificidad en la campaña de Freixo: su llamado a la población carioca a ocupar las calles, es decir, se hace presente on-line pero también off-line. El evento fue transmitido en vivo a través de las redes sociales, pero Marcelo Freixo convocó a sus seguidores para que lo siguieran inclusive a la vida real, presentándose al centro de Rio de Janeiro y participando así de alguna forma en el debate "alternativo".

La cuestión sobre el financiamiento colectivo de la campaña también se hace muy presente en las redes sociales y tiene un rol fundamental en la estrategia de comunicación de Freixo. De los 43 videos analizados, 4 tratan el tema y llaman a los electores a participar como donadores. Sobre este punto se observaron dos aspectos. Primero, todo el discurso es formulado colocando en evidencia la importancia de ayudar financieramente la campaña, al mismo tiempo se pone el acento en el hecho que la participación del elector/ciudadano no es solo eso. Es decir, observamos una tentativa de decir de una cierta forma: "no estamos pidiendo solamente dinero" o "no se trata solo de dinero". A nuestro parecer la campaña de Freixo repite aquel famoso dicho "el dinero es importante, pero no es todo", sin poder ser llamado como "oportunista". Por esta razón, repetidas veces vemos frases como "você que sonha uma cidade diferente, que tem pertencimento nesse projeto que é seu, que é meu, que é nosso, pode financiar" ".

Junto con esta idea, encontramos que en la historia del PSOL, no se aceptan donaciones de empresas desde 2015, gracias al suceso del financiamiento colectivo de Freixo en la campaña de aquel año. Otra característica presente en los videos que tratan de las donaciones hacen una polarización creada entre Nos versus ELES, todo discurso esta bajo este modo de funcionamiento: nosotros no aceptamos donaciones de empresas, para ellos es una novedad, nosotros somos libres y no debemos favores a nadie, ellos tienen "o rabo preso" nosotros soñamos con gobernar con la participación activa de todos, ellos gobernaron con empresas, bancos y contratistas.

Cabe señalar que al final de las elecciones, la campaña de Freixo se transformó en la con mayor recaudación por financiamiento colectivo de Brasil. El candidato recaudó 1,8 millones de reales, a través de la plataforma "Eu financio Freixo", sumando más de 14 mil donadores ${ }^{5}$.

Actualmente, en el sitio es posible verificar cómo cada parte del dinero fue gastada, la parte destinada a la comunicación cuenta con el segundo mayor gasto, sumando $40 \%$ del monto.

4. Ver, por ejemplo los videos publicados los días 3 y 4 de agosto.

5. Ver: https://eufinancio.marcelofreixo.com.br/ 
Otra característica de la campaña, como ya citamos, es que Marcelo Freixo y su equipo intentaron transformar el poco tiempo de propaganda electoral en televisión en un argumento a su favor. Queremos decir con esto que Freixo justificaba tener poco tiempo en la TV justamente por no ceder a alianzas de interés. Con esto su gobierno no comenzaría debiendo favores a quien sea. Una vez más el NOS y ELES, es reforzado frecuentemente por Freixo, para decir que en política, como dice el dicho popular, no todos somos "farinha do mesmo saco".

Durante todo el primer turno, su discurso esta fuertemente dirigido al PMDB y a su candidato Pedro Paulo, que se vo envuelto en un episodio de supuesta violencia doméstica. En sus videos, Freixo repite frases como: "Eles (o PMDB) estão ha 10 anos no poder"; "o valentão do PMDB tem 30 inserções por dia e 3 minutos e meio. Nos temos 30 segundos. E ele não vai conseguir ganhar da gente pro segundo turno" 6 .

Como mencionamos anteriormente, Freizo utilizó el hecho de tener poco tiempo en televisión como una cualidad de su campaña, e intentó, en diversas ocasiones, proponer al telespectador un movimiento de "migración mediática". Por ejemplo, cuando en una emisora de televisión en candidato del PSOL, invita al espectador a cambiar la televisión por internet: "MUDE PARA A INTERNET, CANAL 50. A GENTE SE VÊ LA!". En todos estos momentos las frases de despedida marcaban una especia de encuentro con el elector/espectador, como por ejemplo: "até la", "te vejo la", "a gente se vê la" etc. De esta forma, en los videos "en vivo" hechos a través de la plataforma de Facebook, Freixo agradece el hecho de tener que migrar a intenet, un espacio, según el, "mais democratico e interativo" 7 .

Este movimiento propuesto por Marcelo Freixo, de salir de la pantalla de televisión y con eso, no tenerla exclusivamente como fuente de información, va a completarse enseguida con otro movimiento, el de salir de las redes para ir a las calles. Al analizar los videos publicados en su página de Facebook, podemos percibir que, a partir del mes de septiembre, el candidato del PSOL, comienza a poner más claramente énfasis en la cuestión de la participación popular. Freixo destaca que el elector puede encontrar en las redes y el las calles su agenda, su agenda pasa a ser divulgada con más frecuencia en actos políticos que se hacen más presentes: "comicios na Lapa", "caminhadas no Aterro do Flamengo", visitas a las comunidades populares etc. El día 24 de septiembre, por ejemplo, tenemos el video "Já apresentou o \#Freixo50 para quem ainda não o conhece?", en él Eliza Lucinda, actriz y poetisa afirma que la campaña de Freixo fue un gran éxito. Ella explica:

"sucesso de publico. Sucesso nas pesquisas. A mais curtida. A mais compartilhada. Mas nosso tempo de TV é curtinho e tem muita gente sem internet. Por isso que eu te peço uma coisa: apresente o Freixo para quem ainda não conhece o Freixo. E peça o voto no 50. Peça para sua mãe, sua avo, seu vizinho. Peça até para quem você nunca viu antes. Se cada um de nos conseguir um voto a gente chega no segundo turno. Freixo 50, segundo turno, é possivel".

Podemos concluir entonces, una clara preocupación por transformar el buen desempeño online en compromiso y participación off-line.

6. Ver por ejemplo, los videos publicados el 01/09 y el 01/10, respectivamente.

7. Ver por ejemplo el video publicado el 02/09. 


\section{Sacar a la luz la evasión fiscal, "la próxima revolución será digitalizada"}

La filtración de los documentos de "Mossack Fonseca" se realizó en dos etapas, primero se enviaron de 11,5 millones de documentos en el que se encuentran al menos 200 mil sociedades Offshore que funcionan en más de 200 países (Fuente ciperchile.cl). Estos documentos se entregaron en 2015 al diario alemán "Süddeutsche Zeitung", quienes a su vez los envían al icij "Consorcio internacional de periodistas de investigación", que trabajaron en colaboración con 109 medios en el mundo. Finalmente, la información fue publicada el 3 de abril del 2016, figurando como la mayor filtración de documentos de la historia reciente ${ }^{8}$.

En el caso de Panamá estas cuentas funcionan para conservar dinero de origen ilícito, pero además para eludir impuestos en los países donde se realizaron los negocios que dieron fruto a capitales colosales. Como señala Perrot (2016) este tipo se cuentas funcionan para "las actividades manejadas fuera de las fronteras o para los capitales tratados en el extranjero que permite aplicar reglas diferentes, más permisivas en términos de fiscalidad o de control" (Perrot, 2016: 32). Lo anterior no es calificado de un delito penal ya que no es ilegal, sin embargo, esta al menos al margen de la ética. Empresarios, figuras publicas y sobretodo políticos mantienen un discurso tajante frente al pago de impuestos en sus países, pero sus acciones parecen ser, al menos, contradictorias.

Recordemos que Sebastián Piñera en el foro por la fundación "Ecuador Libre"en septiembre 2016, planteaba :
"yo creo que es muy importante que los paraísos fiscales desaparezcan, porque muchas veces los paraísos se utilizan para o actividades reñidas con la ley y con la moral, como la lavado de dinero u ocultamiento de dineros que provienen del narcotráfico o el crimen organizado. O muchas veces se utilizan para evadir impuestos... y por tanto, yo sí creo que debiesen desaparecer los paraísos fiscales" (Entrevista a Sebastián Piñera, Foro "Ecuador libre”, 2016).

Un año después, el mismo Piñera respondía en un programa de televisión de amplia audiencia con una metáfora relativa al uso de los paraísos fiscales, diciendo: "los paraísos fiscales son como un bisturí, se pueden usar para operar o para degollar", más adelante agrega: "lo que yo dije fue que los paraísos fiscales no pueden ser utilizados para lavado de dineros, para el terrorismo o para narcotráfico...". ("Piñera contra las cuerdas en "Tolerancia cero" por platas en paraísos fiscales: cayó presa de sus propias palabras", art. 12 junio 2017). Sobre este punto, los artículos de "El Mostrador", retoman las respuesta y declaraciones de Sebastián Piñera, planteando reiteradamente el desfase entre discurso-acción ${ }^{9}$, por ejemplo, "No es primera vez, ni será la última, que constatemos una incongruencia entre lo que se afirma y lo que se hace" ("El ex presidente Sebastián Piñera y los paraísos tributaros" art. 30 noviembre 2016). O también:

8. Como lo señaló por ejemplo Edward Snowden en su cuenta oficial de Twitter "Biggest leak in the history of data journalism just went live, and it's about corruption" (Cuenta de Twitter oficial de Edward Snowden, 3 abril 2016, citado por (Obermayer y Obermaier, 2016: 392).

9. Esta misma cuestión es también replicada por el denunciante de los Panama Papers, "una cosa es exaltar las virtudes de la transparencia gubernamental en cumbres y en grandes discursos, pero otra cosa es realmente implementarla" (Carta "La revolución será digitalizada" de "John Doe", el denúnciate de los "Panamá Papers", 6 de mayo 2016). 
"buena parte de quienes aparecen en esos documentos son personas que, por la posición que poseen en la esfera pública, en los medios, en la política, en la empresa, suelen subrayar a nivel del discurso los valores y las virtudes sobre las que se sostienen las instituciones; pero al mismo tiempo, se sabe ahora por los Panamá Papers, aprovechan la menor oportunidad para hacer excepción a ellos cuando el pudor o los impuestos se lo aconsejaban"( "Peña y Panamá Papers: "lo que más llama a escándalo es el hecho de que muestran que la vida social y política es una maleta de doble fondo”, art. 10 abril 2016).

A su vez, cabe mencionar que cualquier investigación a alguna de las empresas situadas en paraísos fiscales se torna compleja ya que existe el llamado "secreto bancario" que apela a la protección de la esfera privada, en el caso de panamá es la "Ley 32 (sobre sociedades anónimas) asegura la confidencialidad sobre los activos, transferencias y sobretodo los propietarios de empresas, y otorga la extensión de impuesto a sociedades anónimas" (Obermayer y Obermaier, 2016: 21). Ahora bien, como plantea Perrot (2016), "el problema internacional aparece cuando la instancia que pide levantar el secreto bancario es una administración fiscal o el órgano judiciario de terceros países" (Perrot, 2016: 34). Esto ocurrió en algunos casos chilenos ${ }^{10}$, dentro ellos, el que llamó principalmente la atención fue el de Sebastián Piñera quien, una vez que salieran a la luz pública los datos, tuvo que admitir su vínculo con "Mossack Fonseca". Lo llamativo del asunto es que Sebastián Piñera fue presidente de Chile, entre los años 2010 y 2014, momento donde estas empresas de encontraban activas.

Además, el análisis del corpus mostró que a lo largo de los artículos, Sebastián Piñera pasa de ser "designado" como "el ex presidente de chile" a "empresario", e irónicamente calificado como "un buen empresario". Estas designaciones tienen una connotación negativa cuando se asocia este término a un "funcionario público" ya que, este último, debiera trabajar por el bien de todos y no por el lucro personal. En un artículo del 16 de noviembre 2016 de "El Mostrador ·se cita: "es incompatible ser empresario y político". Más adelante se agrega: "[Piñera] como buen empresario, privilegia el lucro personal antes que los intereses del pueblo que pretende representar" ( "Navarro presenta proyecto que impide ejercer cargos públicos a quien tenga dinero en paraísos fiscales”, art. 16 noviembre 2016).

Las filtraciones de los "Panamá Papers" permitieron evidenciar el vínculo entre: política, empresa, y la evasión de impuestos. En los artículos, la tematización reiterada de las consecuencias de este vínculo, cuestiona explícitamente el límite de la legalidad y de la ética, límite que las figuras políticas no debiesen traspasar. Por ejemplo, en un artículo del 15 de noviembre del 2016 se plantea:

10. "Entre los beneficiarios chilenos de las sociedades offshore creadas por Mossack Fonseca aún activas, figuran el ex presidente de la Confederación de la Producción y el Comercio (CPC), de la Sociedad Nacional de Minería (Sonami), y socio del ex jefe financiero de la DINA, el abogado Alfredo Ovalle Rodríguez; el empresario Isidoro Quiroga Moreno, quien ha hecho millonarios negocios con la venta de derechos de agua entregados por el Estado (ver reportaje de CIPER); el dueño de la empresa El Mercurio S.A.P., Agustín Edwards Eastman; el ex ministro de Hacienda, candidato presidencial y hasta hace poco director de Soquimich, Hernán Büchi Buc; la familia Calderón Volochinsky, controladora de la empresa de retail Ripley; y los empresarios de las apuestas y juegos de azar, Luis y Lientur Fuentealba Meier, entre otros" ("The Panama Papers": Los secretos de chilenos en paraísos fiscales salen a la luz", ciperchile.cl, 4, abril, 2016). 
El rol de internet para romper el silencio: el ejemplo de dos casos en américa latina, Marcelo Freixo...

"Sebastián Piñera nunca deja de sorprender, rompe todos los estándares éticos y morales. Él gobernó cuatro años en nuestro país, pidiéndoles a todos que pagaran impuestos y él mismo evadía el pago que les exigía a los empresarios de este país", agregó el diputado Soto" ("Paraísos fiscales: el nuevo flanco que se le abre a Piñera tras revelarse negocios en Perú", art. 15 noviembre 2016).

Esta tensión entre función pública y empresariado se polariza en dos figuras políticas en los artículos publicados entre el 16 y el 28 de noviembre 2016. Por un lado, se encuentra a Sebastián Piñera ("el acusado") y por otro lado, al senador Alejandro Navarro ("el acusante), el último designa a Piñera como "hombre de finanzas". Designación en la que confluye la tensión empresario-funcionario público, haciendo referencia a una polémica entrevista donde se constata que Piñera tenia un "terminal Bloomberg" en la Moneda ${ }^{11}$ :

El análisis también mostró que durante los primeros artículos (desde el 6 de abril 2016 hasta antes del 15 de noviembre 2016), los hechos sacados a la luz de los "Panamá Papers" no sorprenden a la opinión publica, enunciando el hecho como: "una realidad conocida", "no es algo novedoso", "no debiese sorprender a nadie". Lo anterior parece contradecir el hecho que Chile se jactó durante años de no ser un país corrupto frente a sus vecinos latinoamericanos. Por ejemplo:

"La relación entre dinero y política no era concebida como un problema. [... ] Era una sociedad que todavía creía que la "creación de riqueza" por parte de los sectores acomodados radicaba en gran medida en sus esfuerzos y capacidades; en el mérito propio de las personas y su incólume voluntad para emprender. ("Dinero y política”, art. 17 noviembre, 2016).

Sin embargo, la "sorpresa" se observa a partir de los artículos del 15 de noviembre 2016 donde se vincula a Sebastián Piñera no solamente con la acumulación de su capital en paraísos fiscales, pero también con inversiones en empresas pesqueras de Perú al momento del la delimitación marítima entre Chile y Perú en la Haya. El corpus muestra una designación de este hecho como un "destape" entendido como el acto de hacer público un hecho. Por ejemplo un artículo del 15 de noviembre del 2016, plantea: "Un verdadero tsunami político se vivió ayer. El destape de la inversión en una pesquera peruana por parte del ex Presidente Sebastián Piñera" ("Paraísos fiscales: el nuevo flanco que se le abre a Piñera tras revelarse negocios en Perú”, art. 15 noviembre 2016). El "destape" sobre el conflicto entre la función pública y lucro personal bajo la figura de Sebastián Piñera aumentan "la falta de confianza" de la ciudadanía hacia los políticos, evidenciando una "preocupación ciudadana". Por ejemplo, "hoy en día, la confianza en los empresarios, en los supuestos "emprendedores" de nuestro país, está por los suelos" ("Opinión: ¿fue el gobierno de Piñera el más corrupto?”, art. 11 abril 2016). En este punto, el corpus de artículos evidencia una separación entre la "clase política" incluido los empresarios (ellos) y los ciudadanos (nosotros) a quienes también pertenece la riqueza de Chile. Lo anterior hace eco de las palabras de Zucman (2013), para quien el aumento de la desigualdad tiene un vínculo con los paraísos fiscales. Según él, "los paraísos fiscales han estado en el centro de la crisis financiera, presupuestaria y democrática" (Zucman, 2013: 12). Cuestión de la cuál Sebastián Piñera no quería ser responsable, pero que

11. Ver artículo: "Navarro responde a Piñera: "Miserable es ganar dinero mientras Chile pierde territorio", art. 28 noviembre 2016. 
gracias a investigaciones que intentan "romper el silencio", (realizadas y difundidas ampliamente por internet) el actual candidato presidencial ${ }^{12}$ debió obligadamente aceptar.

Para concluir, cabe señalar que el título de este apartado: "La próxima revolución será digitalizada", proviene de una frase de quien es la fuente de la filtración de los "Panamá Papers", quien luego de recibir innumerables críticas focalizadas en el "derecho a la privacidad" responde subrayando que la desigualdad en los ingresos es un problema de orden mundial. Las riquezas y los negocios ilícitos se gestionan à través de empresas fantasmas desde Panamá con uno de los bufetes de abogados "Mossack Fonseca". En este marco, "los Panamá Papers son, sin más, un síntoma evidente de la moral decaída y progresivamente enferma de nuestra sociedad" (Carta "La revolución será digitalizada" de "John Doe", el denúnciate de los "Panamá Papers", 6 de mayo 2016). Recordemos que según Zucman (2013) la riqueza alojada en los paraísos fiscales (no tan solo en Panamá) alcanzaría el 8\% del patrimonio financiero mundial.

\section{Conclusiones}

Este trabajo propuso cuestionar cómo internet puede ser una herramienta para romper el silencio y así influir en la opinión pública. En los dos casos anteriormente presentados se observó que internet contribuye a cuestionar el funcionamiento de las democracias actuales y puede ser utilizado como una herramienta para quebrar, en cierta forma, los estándares de las informaciones que son impuestos por los medios tradicionales. Con lo anterior, se busca reivindicar la transparencia. Como dicen Cardon y Granjon (2013),

"La participación ciudadana en internet da en principio armas nuevas a una crítica vigilante y minuciosa del trabajo de los medios, de acuerdo con la tradición de la critica contrahegemónica. Ella abre, por una parte, los espacios de visibilidad nuevos para las representaciones de lo real que no encuentran un lugar en la agenda de los medios tradicionales" (Cardon, Granjon, 2013: 122).

Por un lado, las denuncias de los Panamá Papers dejaron entrever las incongruencias de una figura política como Sebastián Piñera provocando en la ciudadanía una "desconfianza" en la "clase política" y en la democracia en general. En el caso de Brasil, la "obligada" campaña de Freixo en internet demuestra el disfuncionamiento de una parte fundamental del proceso democrático (tempo de propaganda autorizada) y la dificultad que los candidatos emergentes encuentran para entrar en el ejercicio democrático, por ejemplo, un debate. Lo anterior, favorece a los que están en el poder, dificultando una renovación de la clase política.

Por otro lado, estos casos muestran que en alguna medida se consiguió romper con las barreras del silencio gracias a internet. Sin embargo, la visibilidad en el espacio público, no esta solamente

12. El mismo ex presidente luego de ser vinculado a paraísos fiscales (no tan solo en Panamá) lanza su candidatura como pre-candidato presidencial (el 21 de marzo 2017), que finalmente gana en las primarias de la derecha del 2 de julio 2017 quedando como el candidato de la coalición de derecha "Chile Vamos", que reúne los partidos Unión Demócrata Independiente, Renovación Nacional, Evolución Política y Partido Regionalista Independiente, entre otros independientes de derecha Actualmente, según la encuesta Adimark (agosto, 2017), Sebastián Piñera obtiene un 32\% de intención de voto, superando por 15 puntos a la candidata del "Frente amplio" que le sigue, Beatriz Sánchez. 
garantizada con internet. Como plantea Cardon (2010) publicidad no es necesariamente un sinónimo de visibilidad. En el caso de América Latina, frente al poder de los medios tradicionales, el camino para conseguir visibilidad es largo. Sin duda, estos dos casos lograron tener cierta visibilidad a través de internet, pero concretamente, Freixo no consiguió ganar la disputa y Piñera se plantea como el candidato victorioso en las próximas elecciones presidenciales.

Para concluir, queda claro, que al contrario de los que algunos piensan, internet tiene que ser visto cada vez más como un espacio de compromiso político que va mucho más allá de una "agenda en-línea". En el caso de Marcelo Freixo, se intentó crear un movimiento donde a groso modo, se intenta que el espectador/elector migre a las redes (en-línea), seguido de un movimiento simbólico donde se propone ocupar no solamente la red sino que también las calles. En el caso de Chile, las publicaciones del escándalo que involucra a Piñera con empresas en paraísos fiscales interfirió en la agenda del país teniendo como consecuencia un aumento en la desconfianza hacia la clase política además de una demanda de transparencia.

\section{Bibliografía}

Cardon, D. (2010). La démocratie internet. Paris: Seuil.

Cardon, D. \& Granjon, F. (2013). Médiactivistes. Paris: Presses de Sciences.

Castells, M. (2012). Redes de indignación y esperanza. Madrid: Alianza editorial.

Charaudeau, P. (1995). Une analyse sémiolinguistique du discours. Revue Langages, 29(117), 96-111.

Charaudeau, P. (2011). Les médias et l'information. L'impossible transparence du discours. Bruxelles: De Boeck.

Charaudeau, P. (2013). El discurso de la información. La construcción del espejo social. Barcelona: Gedisa.

Fraça, V. (2012). O acontecimento e a mídia. Galaxia (São Paulo, Online), (24), 12.

Gomes, W.; Fernandes, B.; Reis, L.; Silva, T. (2009). Politics 2.0. A campanha on-line de Barack Obama em 2008. Rev. Sociol. Polít., out., 17(34), 29-43.

Heinderyckx, F. (2011). Obama 2008: l'inflexion numérique. Hermès, La Revue, 1(59), 135-136.

Jamil, F. P. \& Sampaio, R. (2011). Internet e eleições 2010 no Brasil: rupturas e continuidades nos padrões mediaticos das campanhas politicas online. Revista Galaxia, dez., (22), 208-221.

Maingueneau (2011). Analyser les textes de communication. 2e édition. Paris: Armand Colin.

Massuchin, M. G. \& Tavares, C. (2015). Campanha eleitoral as redes sociais: estratégias empregadas pelos candidatos à Presidencia em 2014 no Facebook. Revista Compolítica, 5(2).

Miege, B. (2010). L'espace public contemporain : approche info - Communicationnelle. Grenoble: PUG.

Moirand, S. (2007). Les discours de la presse quotidienne. Paris: Presse universitaires de France.

Obermayer, B. \& Obermaier, S. (2016). Le secret le mieux gardé du monde. Paris: Seuil. 
Perrot, E. (2016). Les paradis fiscaux à l'ombre de la morale. Études, juin, (6), 29-40.

Zucman, G. (2013). La richesse cachée des nations. Paris: Seuil. 